The Politics of Climate Change: Review and Future Challenges

Holger Haibach \& Kathrin Schneider

\title{
Abstract
}

Issues of climate change - its far-reaching effects and urgently needed countermeasures in particular - are becoming an unprecedented challenge for nowadays society. Hence, climate change politics are at the top of the political agenda for all countries around the world. Starting with a short introduction on the history of climate change politics - from the first major conference on the environment in Stockholm, Sweden in 1972, to the negotiations on the United Nations Framework Convention on Climate Change (UNFCCC) in Rio de Janeiro, Brazil in 1992, the Kyoto-Protocol in 1997 and to the recent Conference of the Parties to the UNFCCC in Doha in 2012 - this article critically questions the effectiveness of the UNFCCC, its Protocol and the annual meetings of the parties. Furthermore, the reasons why it appears to be impossible to reach a global agreement on fighting climate change are discussed. The article concludes that the essential burdens lie in the different interests of developing and developed countries, of polluters and those who are mostly affected. On the basis of theses global disagreements, the article finally outlines possible future challenges for global climate politics and suggests some deeply needed provisions, which can only succeed through a trustful and intense cooperation among all countries of the world.

\section{A. Climate Change as a Global Political Issue}

Climate change has become an unprecedented challenge for humankind due to its severe consequences for our environment. Especially in the last three decades, global warming has been increasing rapidly, predominantly caused 
by the combustion of fossil fuels such as coal, oil and gas, as well as by continuing deforestation. ${ }^{1}$

The frequency and strength of environmental disasters like floods, hurricanes, and long-lasting periods of heat and drought have to be taken as serious warnings. The famine in the Horn of Africa, recent floods in Thailand and Central America, Hurricane Sandy in the Northeastern United States (US)and the Caribbean in October 2012 are only a few shocking examples of how our planet is affected by human intervention.

Consequently, the issues of climate change, its far-reaching effects and the urgently needed countermeasures nowadays top the political agendas in many countries around the world.

What makes climate change different from any other political topic is the mere fact that the climate crisis cannot be solved by a single world power or a group of states. The whole of humankind has to cope with the consequences on a planetary scale. Hence, adequate measures to restrict the effects of climate change are needed, and those can only succeed via a global approach. ${ }^{2}$ Yet, although everyone seems to be aware of the necessity of global cooperation, finding a supranational consensus is practically impossible, as the political and economic interests of countries around the world interfere in finding an adequate solution. Thus, the progress in international negotiations is very slow - if discernible at all.

Consequently, over the last few years, the scepticism regarding insufficient progress in climate politics has reached a new level. Especially in the post-Kyoto process, it has become obvious that the different areas of interest of developing and developed countries, of polluters and those who are mostly affected, as well as of the new emerging powers have made it nearly impossible to reach a consensus on a common strategy, let alone effective and efficient countermeasures. Some critics even argue that the ecological footprint and the costs involved have far outweighed the outcome of conferences on climate change in recent years. In order to understand the current situation - which may be described as a deadlock - it is necessary to briefly reconsider the history of international climate change negotiations. The different spheres of interest of all parties involved also need to be assessed.

1 See Hirsch (2012:2).

2 (ibid.:2). 


\section{B. From Polluting the Environment to the First Steps of Action: A Long Way}

Ever since the beginning of industrialisation roughly 150 years ago, humankind has affected the global climate. These effects on the environment can no longer be reversed. Hence, many states, and developing countries in particular, have to face the principal environmental challenges of deteriorating air and water quality, inadequate soil conservation, and insufficient food supply. With increased frequency, even more challenging problems appear, including acid precipitation, Arctic haze, depletion of the stratospheric ozone, species extinctions and global warming. Especially in areas like sub-Saharan Africa, the existing problems like migration and disease have been severely aggravated.

The scarcity of natural resources such as oil and their rapidly increasing prices are critical reasons for seriously considering the question as to whether economic growth is infinite by definition. At the same time, the idea of sustainability emerged, as did the concept of the fair distribution of wealth amongst the countries and continents of the world. All of this culminated in the Club of Rome initiative, which stated that growth had to have its limits and that it came with a price tag. Economic growth cannot happen at the expense of sustainability. Whatever political stance one takes regarding the findings of the Club of Rome in 1968 and their political reactionism, the serious environmental response to extensive industrial development served the purpose of putting the issue of climate change high on the international agenda. In particular, the disaster at the nuclear power plant in Chernobyl in 1986 and its effects on flora and fauna throughout Europe made it abundantly clear that man-made interventions and their consequences do not take into account territorial or ideological boundaries, but call for an international response.

However, a conceptual approach of the United Nations (UN) was, even back then, still not under way. Initiatives tackling climate change were only taken in the 1980s when the issue emerged on the international political agenda, ${ }^{3}$ although they could build on efforts made in the early 1970s. At the first major conference on the environment, namely the UN Conference on the Human Environment (UNCHE) held in Stockholm, Sweden, in 1972, representatives of 113 states underpinned that further environmental challenges could only be overcome through extensive international cooperation.

3 See Mayr (2009:10).

https://doi.org/10.5771/9783845242774_357, am 26.04.2023, 14:55:48 
Consequently, participants agreed on a Declaration which incorporated not only 26 common principles, ${ }^{4}$ but also provided further guidelines for action concerning issues on environment and development. Twenty years later, in June 1992, heads of state or government convened at the UN Conference on Environment and Development (UNCED) in Rio de Janeiro to pass the UN Framework Convention on Climate Change (UNFCCC). This Convention is still the definitive international treaty whose object is the long-term aim to stem climate change - and the stabilisation of greenhouse gas (GHG) concentrations in the atmosphere in particular - by means of international cooperation through the principle of common but differentiated responsibilities and respective capabilities. ${ }^{5}$ Hence, the Rio Conference, also known as the Earth Summit, marked the institutional heyday of global climate politics.

\section{Post-Rio: Down the Road to Nowhere}

Since the ratification of the UNFCCC in 1992, its signatories have been meeting annually at Conferences of the Parties (COPs) to discuss progress and further steps in tackling climate change. The first such conference (COP1) took place in Berlin, Germany, in 1995. COP1 saw the adoption of the Berlin Mandate, which incorporated a review of initial negotiations as well as new commitments. With hindsight as to the effectiveness of the first two COPs - the second having taken place in Geneva, Switzerland, in 1996, one criticism is that both merely emphasised the necessity of action rather than elaborating on ground-breaking commitments to combat serious climate change. ${ }^{6}$ The first legally binding obligations concerning the reduction of GHG emissions were set at COP3 in Kyoto, Japan, in 1997, when the national representatives in attendance signed what became the Kyoto Protocol. Under the Protocol, the 37 leading industrial countries committed themselves to decreasing GHG emissions by an average of $5 \%$ within a set

4 The principles focus, amongst other things, on the assertion of human rights, the prevention of oceanic pollution, and the financial support of developing countries. For more details, see http://www.unep.org/Documents.Multilingual/Default.asp?Docum entID=97\&ArticleID=1503, last accessed 19 November 2012.

5 See http://unfccc.int/essential_background/convention/background/items/1355.php, last accessed 17 November $20 \overline{1} 2$.

6 For the complete COP1 Report, see http://unfccc.int/resource/docs/cop1/07a01.pdf, last accessed 17 November 2012. 
target period between 2008 and 2012, compared with the level in 1990. To date, the Kyoto Protocol is "... generally seen as an important first step towards a truly global emission reduction regime that will stabilise GHG emissions, and provides the essential architecture for any future international agreement on climate change." 7

As it was not clear how many states would ratify the Protocol, the ensuing annual COPs - whether in Buenos Aires in 1998, The Hague in 2000, or Bonn in 2001 - primarily targeted filling gaps in the Protocol and preparing for ratification, which was originally envisaged for 2000. Unforeseen complications arose shortly before the Sixth Climate Change Conference started in Bonn, in 2001, when the US, the biggest emitter of GHGs worldwide at the time, rejected the ratification of the Kyoto Protocol. The then newly elected President, George W. Bush, justified the US's decision by raising concerns regarding the potential damage to the US economy due to the Protocol's requirements. During the Bonn Conference, UN member states nonetheless tried to find a satisfactory outcome, despite having to cope with refusal or indifference from a large number of states parties. The Kyoto Protocol finally entered into force in February 2005, and had been ratified by 191 states parties by September $2011 .{ }^{8}$

Ten years after Rio, the World Summit on Sustainable Development informally known as Rio +10 - took place. Representatives of 192 countries met in Johannesburg, South Africa, not only to recapitulate Agenda 21 - an unprecedented global plan of action for sustainable development decided during the Rio Summit, but also to discuss further steps and targets for better implementation. Moreover, states parties which had already ratified the Kyoto Protocol again called on others to do likewise. Canada announced it would ratify the treaty, while other countries such as Australia, China and Russia reaffirmed they would give it their consideration. ${ }^{9}$

In addition to the Earth Summit, UNFCCC member states continued their meetings at annual COPs. Although a failure with respect to being a followup on Kyoto, COP15 in Copenhagen, Denmark, in 2009 made some progress referring to "negotiations on the infrastructure needed for effective global climate change cooperation" and "improvements to the Clean Development

7 See http://unfccc.int/kyoto_protocol/items/2830.php, last accessed 19 November 2012.

8 (ibid.).

9 See http://www.earthsummit2002.org/, last accessed 19 November 2012. 
Mechanism of the Kyoto Protocol". ${ }^{10}$ Moreover, participants decided on the Copenhagen Accord, which clearly expressed a political intent to constrain carbon dioxide emissions and respond to climate change in both the short and long term. States parties committed to limiting the increase of the global average temperature by $2^{\circ} \mathrm{C}$. However, no sufficiently legally binding commitments were made regarding the reduction of GHGs in order to reach that goal.

Additional progress was achieved after COP16 in Cancun, Mexico, in 2010, and during COP17 in Durban, South Africa, in 2011, when participants agreed to adopt a universal legal instrument on climate change. The instrument was to be instituted by 2015 and take effect in $2020 .{ }^{11}$ Earlier considerations to expand the existing framework, namely the Kyoto Protocol, could not be agreed on as extensive resistance was put up by emerging countries as well as the US.

A further decision taken in Durban was to set up a Green Climate Fund to assist developing countries with implementing mitigating measures. The target was an amount of 100 billion US $\$$ by the year $2020 .{ }^{12}$ Six countries/ cities applied to host the Fund: Warsaw (Poland), Mexico City (Mexico), Geneva (Switzerland), Namibia (Windhoek), Germany (Bonn), and South Korea (Seoul), whereby the latter proved to be the successful applicant.

COP18 in Doha, Qatar, continued the ongoing discussions on commitments with very little - if any - success. Only 37 of the nearly 200 participating countries were willing to bind themselves to reducing their GHG emissions in the framework of the second Kyoto phase until 2020. These 37 countries currently emit only $15 \%$ of the world's GHGs. The biggest polluters, amongst them Canada, China, Japan and the US, were not willing to further reduce their emissions. ${ }^{13}$ After 18 annual COPs ${ }^{14}$ to date, it is time to put all the commitments made to a reality test.

10 See http://unfccc.int/meetings/copenhagen_dec_2009/meeting/6295.php, last accessed 19 November 2012.

11 See http://unfccc.int/meetings/durban_nov_2011/meeting/6245.php, last accessed 19 November 2012.

12 See http://cancun.unfccc.int/financial-technology-and-capacity-building-support/n ew-long-term-funding-arrangements/, last accessed 8 January 2013.

13 See Ruppel (2013).

14 2001: COP7, Marrakech, Morocco; 2002: COP8, New Delhi, India; 2003: COP9, Milan, Italy; 2004: COP10, Buenos Aires, Argentina; 2005: COP11/MOP 1, Montreal, Canada; 2006: COP12/MOP2, Nairobi, Kenya; 2007: COP13/MOP3, Bali, Indonesia; 2008: COP14/MOP4, Poznań, Poland; 2009: COP15/MOP5, Copen- 


\section{Setbacks and Achievements of the Global Action against Climate Change: The Real World}

Taking into account the mounting criticism on formal climate change negotiations, one could easily conclude that not much has been achieved over the last 20 years. Moreover, the prospect of anything further being achieved in the next 20 seems equally problematic, since there are other, allegedly more urgent issues to which the international community needs to attend. Ever since the world plunged into a financial and economic crisis in $2008 / 2009$, the attention has tended to move away from environmental issues and shift to short-term troubleshooting in the areas of finance and the economy. Huge amounts of money are spent on stabilising markets and the economies of entire countries. Furthermore, economic strongholds like the European Union (EU) are struggling to maintain their stability. The effect of the crisis is twofold: the EU is not only experiencing a scarcity of resources to appropriate towards climate change matters, but it also - having been one of the driving forces behind negotiations on the issue - now finds itself in a precarious situation by the debates prevailing on its future financial framework.

Thus, in spite of a continued interest in climate action by non-governmental organisations and environmental movements, the world appears to be moving away from a safe and equitable climate future faster than ever before. Or at least so it seems. Political leaders are fully engaged with the global financial crisis and economic recession. There is a decrease in public interest. Furthermore, there is no master plan on the horizon to somehow break up the situation of deadlock that the negotiations are in right now. The million dollar question remains unresolved, however: how can one streamline the divergent interests of the various parties to the process?

To address this question, it may be worthwhile to explore the origin of these diverging interests. COP participants, for instance in Doha, failed to set legally binding commitments to reduce atmospheric concentrations of GHGs for individual countries: they merely agreed on guidelines that had no legal force. Hence, industrial countries did not really consider these targets as obligatory, but accepted them in a more moral sense. This poses questions regarding the annual COPs and their effectiveness. Although, with

hagen, Denmark; 2010: COP16/MOP6, Cancún, Mexico; 2011: COP17/MOP7, Durban, South Africa; 2012: COP18/MOP8, Doha, Qatar. For more detail see http://unf ccc.int/meetings/items/6240.php, last accessed 19 November 2012. 
the Kyoto Protocol, the UNFCCC states parties for the first time decided on a binding international treaty regarding limits of GHGs emissions, non-ratification or delayed ratification by quite a large number of countries challenged the effectiveness of the Protocol from the very outset.

In particular, the rather surprising decision by the US not to ratify the Kyoto Protocol in 2001 made it difficult to proceed, as it became questionable whether the treaty would still make sense without the participation of the world's biggest polluter and one of the most influential leaders in economic issues. ${ }^{15}$ Predictably, the US's withdrawal from the Protocol set the example for other countries not to ratify the treaty. It was only in 2005, with Russia's ratification - ten years after Kyoto - that the treaty finally became effective. It took another three years for the Protocol's first commitment period to start, i.e. the one ending in 2012. So it was to be expected that the Protocol's long-term vision to keep global warming below the threshold of $2^{\circ} \mathrm{C}$, or even $1.5^{\circ} \mathrm{C}$, could simply not be reached within the treaty's existing framework. ${ }^{16}$ The situation at hand is aggravated by the fact that emerging powers and big polluters like China never signed the Kyoto Protocol, and have yet to be convinced that globally decided commitments are indispensable to find a common way out of the climate crisis.

\section{E. Essential Burdens: The Gap between the Haves and the Have-Nots}

Although the idea of annual COPs in which all states parties participate may be considered a positive development, the results of these meetings have been relatively disappointing. Hence, massive conflicts of interest and an absence of political will on the part of governments to agree to a fair, farreaching and binding commitment for all countries explain why especially COP15 in Copenhagen in December 2009 failed so spectacularly. Powerful states like China, the US, and further emerging economies again opposed common, binding emission reduction obligations, and insisted on voluntary commitments in a so-called pledge-and-review arrangement. Once again, industrial states considered the demands as economically harmful, and believed this justified their position not to commit. Rather predictably, the voluntary provisions have so far failed to address global warming, and in

15 Cf. Böhringer (2001:4).

16 (ibid.:9). 
addition the principle of common but differentiated responsibilities and respective capabilities, which was emphasised in the Bali Action Plan of 2007, lost its importance. ${ }^{17}$

The more the world has to cope with the consequences of global warming, the more this issue moves from an economic and environmental problem to a social challenge, as economic injustice and global poverty collide with the overconsumption and the desire for ever-increasing wealth. The biggest contrast can be found in the fragile social balance between industrialised and developing countries, or the gap between the rich North and the poor South. Ironically, the poorest, who bear little or no responsibility for the climate problem, have to face the most dire, even catastrophic, consequences of climate change and are unable to cope with them. Tackling the climate crisis seems to have changed to a system of the 'survival of the fittest', in which winners and loser are preordained. Developed countries stand to lose in the short term; but from a long-term perspective, we might all lose: causes are often generated locally, but the harm is felt on a planetary scale.

Despite the recognition that combating climate change can only succeed via global cooperation, it seems almost impossible to realise as developed countries, in particular, focus on personal interests and benefits. Most of them fail to take on the double responsibility of not only reducing their own emissions, but also providing adequate, reliable financial measures for emission reduction and adaption in poorer countries.

\section{F. Things Happen for a Reason: Key Players and their Motives}

As the world's second largest single emitter of GHGs after China, the US has a considerable potential for action and should take the lead in reducing their domestic emissions by accepting reduction targets and pledging financial support for developing countries. ${ }^{18}$

However, instead of taking a step towards global climate protection, the US still refuses to accept the commitments of the Kyoto Protocol. The US Senate justifies its position by saying that treaty negotiations were held under unfair conditions because developing countries - among others China and India - were excluded from emissions obligations within the Protocol. ${ }^{19}$

17 See Fuhr et al. (2011:9).

18 See Donner et al. (2007:4).

19 (ibid.:5). 
These circumstances also raised the Senate's fear that economic growth in the US would stagnate, and that the threshold countries mentioned - which made no commitments to reduce their emissions at all - were unfairly advantaged by the treaty. ${ }^{20}$

Thus, instead of striving for a more climate-friendly industrial economy, the US focused on the promotion of research and innovation for climatefriendly technologies. The approach to develop more such technologies and types of energy generation is also supported in the Asia-Pacific Partnership on Clean Development and Climate (APP) signed in 2005, which aims at pushing climate-friendly technologies through intergovernmental cooperation.

Further typical strategies of US climate politics are tax concessions, voluntary partnerships between the private and public sectors, and international cooperation, the latter being integrated into federal strategies such as the Climate Change Technology Program and the Climate Change Science Program, both initiated in 2002. ${ }^{21}$

Nevertheless, new approaches referring climate politics of the US government were not made over the last years. Indeed, during a speech in 2008, then President George W. Bush hinted at a new climate protection strategy, whereby GHG emissions should not increase until 2025. This position could also be interpreted as the US's first acceptance in principle of an emissions limitation. Nonetheless, the country remains steadfast in refusing to commit to concrete, legally binding requirements, at least until countries like China and India are similarly obliged to reduce their GHG emissions. ${ }^{22}$

Against the relatively regressive attitude of the US as a political and economic unit, various US states - most notably the State of California - agreed to pursue an active climate change policy. Indeed, legally binding caps for GHG emissions have been set in 17 US states. More and more frequently, these legal changes in domestic politics are reflected in cross-party drafts in the US Congress that aim to reduce emissions through binding caps. ${ }^{23}$

When one focuses on current actions in the US, the 2012 presidential elections and, especially, the topics of their campaign debates, it is clear that the climate change crisis - the biggest global issue of all - still seems to

20 See http://www.oekosystem-erde.de/html/klimapolitik.html, last accessed 27 November 2012.

21 See Donner et al. (2007:5-6).

22 (ibid.:7).

23 (ibid.:4). 
enjoy scant priority in US politics. In his election campaign in 2008, President Barack Obama highlighted climate change as one of his priorities; in the 2012 presidential race, almost no reference was made to the issue by the incumbent President or his opponent, Mitt Romney. The only exception was the impact of Hurricane Sandy, where President Obama described climate change as one of its causal factors. Moreover, the Obama Administration did not establish new policies in this regard, so it is yet to be seen whether the re-elected President will make good on his first-term promises during his second term. ${ }^{24}$

Equally unwilling to commit themselves to reduce GHGs in the framework of an international, legally binding treaty are emerging countries and rising powers, including China and India. If one compares the climate policies of China and the US, both countries display similar behaviour towards binding agreements to reduce GHG emissions. The Chinese Government opposed any binding cuts in GHGs during the COP in Copenhagen in 2009, and opted to take its own measures domestically against GHG emissions, predominantly to become more energy efficient.

One of the voluntary commitments offered by China in Copenhagen was to reduce the country's carbon dioxide concentrations to $40-45 \%$ by 2020 . Taking into account that China's total emission of $\mathrm{CO}_{2}$ doubled in the 15year period between 1991 and 2006, it is foreseeable that the set long-term objective to decrease emissions will not be achieved by $2020 .{ }^{25}$

However, China has developed measures to decrease emissions. These include integrating climate change mitigation and adaption in national sustainability strategies and initiatives. Although these guidelines imply that China's political leaders may take climate change seriously, the issue takes no priority over objectives such as national economic development and growth, which aim to lift it out of poverty. ${ }^{26}$ On the international front, China has advocated for common but differentiated responsibilities and respective capabilities, proposing that developed countries be frontrunners in reducing GHG emissions, and that they technically and financially support developing countries. This approach seems to be problematic in a sense that China still

24 See http://www.guardian.co.uk/commentisfree/2012/nov/05/obama-romney-remai n-silent-climate-change, last accessed 6 November 2012.

25 See Harris (2010:2).

26 (ibid.:2). More information on China's policies and actions for addressing climate change are available at http://english.gov.cn/2008-10/29/content_1134544.htm, last accessed 6 November 2012. 
considers itself as a developing country and urges other stakeholders to take action, whereas it replaced the US as the world's largest polluter in 2006. Furthermore, on the grounds of national sovereignty, China is not willing to allow its emissions to be monitored and evaluated in an attempt to reduce them. ${ }^{27}$

Like China, other emerging countries have not as yet committed themselves to the Kyoto process or a respective follow-up. One of the underlying arguments is the fear of losing national sovereignty. Another, perhaps more important one, is that the process as a whole is viewed with suspicion by some countries, because it is seen as an attempt by the previously dominant world economies to maintain their dominance. Reducing GHGs will only be possible at the expense of economic growth, so the argument goes. Closely connected to this is the issue of development. While industrialised countries have had the opportunity to grow without any concern as to the damage they were doing to the world's climate, the prevailing feeling among developing countries is that they should be given the same chance to do so.

For quite some time, the EU has been trying to act as a mediator between conflicting interests and as a driver for progress. Although it is relatively difficult to coordinate the positions of nearly 30 member countries, the EU has managed to come up with a common approach during the various COPs. However, the EU has not always succeeded in making use of its political leverage. During the sometimes chaotic COP15 in Copenhagen, final decisions were taken and final deals struck between China and the US without the EU being involved. COP17 in Durban, on the other hand, showed that the EU and the developing countries have some influence on the process. Had these latter two groups not teamed up and followed a common approach, even the little that was achieved back then would not have been possible.

\section{G. Least Culpable, but Most Affected: The Role of Developing Countries}

If one looks back on the latest disasters as a result of climate change, developing countries have been the ones to suffer most from the consequences. Hence, it is more than understandable that countries in Africa and Latin America, in particular, not only urge the industrialised world to assume their responsibility for global warming, but also insist on their financial support

27 Harris (2010:5). 
for devising measures against climate change. However, with budgets being strained by financial turmoil, climate aid for least-developed countries has become a more challenging task.

In Copenhagen in 2009, industrialised countries agreed to provide nearly US\$30 billion in grants and loans to developing countries to enable them to counteract the effects of climate change, but those commitments expired in 2012. Later on, the Green Climate Fund was set up to raise US $\$ 100$ billion annually by 2020 for the same purpose. However, this Fund is not yet operational, and the money has only been promised. Furthermore, it is to be seen if the money pledged is really 'fresh' money or, as happens frequently in development cooperation, money that was pledged to other, earlier commitments. Where does this leave the developing world? It is to be expected that new financial resources may be available to mitigate the consequences of climate change, in spite of some sentiments in developed countries which question whether developing countries in fact do have a solid strategy to tackle the issue. ${ }^{28}$

One can only hope that the problems experienced by many developing countries (including corruption, weak statehood and infrastructure) will not negatively affect the success of measures to mitigate climate change. In addition, developing countries will have to come up with their own initiatives in respect of becoming less vulnerable to exterior political influences, wherever this is possible. A good example in this respect may be Namibia, a country heavily affected by the impact of climate change. ${ }^{29}$ Although not a big polluter, Namibia has the opportunity to reduce its carbon footprint by making use of its most abundant source of energy: the sun. Solar installations, combined with other sources such as wind or invasive bush, could make the country a role model for self-sufficient, eco-friendly, decentralised energy supply. Yet, in spite of many private initiatives, Namibia still relies heavily on fossil fuel energy sources, which - to make matters worse - are mostly imported. Furthermore, the country lacks a coherent policy and legislation that could endorse the use of renewable energies.

It is precisely these gaps that the support of developed countries could usefully fill by means of knowledge transfer and financial assistance. However, it would be too simplistic to see developing countries only as being on the receiving end or as passive recipients of financial support. The COP17

28 See http://www.huffingtonpost.com/2012/11/25/2012-un-climate-talks-qatar_n_21 88048.html, last accessed 4 December 2012.

29 See Mapaure (2011:289ff.). 
in Durban showed that, if such countries speak with one voice and team up with allies, they could have political leverage and bring some pressure to bear on the largest polluters. This applies to both the US and China. Moreover, since China has embarked on a series of interventions in the quest for new suppliers of natural resources - usually in developing countries - to meet the ever-growing needs of its economy, such countries also have ways and means of taking part actively in negotiations.

\section{H. Future Challenges for Global Climate Politics: Doha and Beyond}

According to a climate study recently published by the World Bank, we are moving directly towards a situation in which the global average temperature will rise by $4^{\circ} \mathrm{C}$ by the end of the 21 st Century. ${ }^{30}$ This greatly exceeds the official aim of limiting the rise in global temperature to below $2^{\circ} \mathrm{C}$ by 2012 , to which the states agreed at a UN climate conference in the Copenhagen Accord some years ago. ${ }^{31}$

As UNFCCC states parties have not complied with the set target, political leaders have been sharply criticised for their ignorance of deeply needed global cooperation, and the progress in counteracting global warming has completely stagnated. Hence, the participants at the COP18 in Doha in 2012 - the first UN climate conference ever in the Arab region - were under particularly intense pressure. ${ }^{32}$

In the run-up to COP18 negotiations, the 195 states parties set themselves key objectives according to which the most urgent task lay in extending the Kyoto Protocol, following the expiry in 2012 of its first commitment period. Other key issues on the agenda concentrated, amongst other things, on strengthening the adaptive capacities of the most vulnerable, producing the financial support pledged to developing countries' climate change mitigation actions, the call for further measures against deforestation, and developing more eco-efficient technologies. ${ }^{33}$

30 See http://www.zeit.de/wirtschaft/2012-11/klimawandel-weltbank-bericht, last accessed 4 December 2012.

31 (ibid.).

32 For more information, see http://unfccc.int/meetings/doha_nov_2012/meeting/6815 .php, last accessed 4 December 2012.

33 Cf. http://unfccc.int/files/press/press_releases_advisories/application/pdf/pr201026 11_cop18_open.pdf, last accessed 4 December 2012. 
As we now know, the outcome was rather poor. The one success - keeping Kyoto legally binding until 2020 - has been diluted by the low number of countries committed to the Kyoto process. Furthermore, the biggest polluters are again not part of the negotiated solution. Moreover, no progress has been made on a new treaty that is supposed to be finalised by 2015. On the other hand, time is running out. In order to limit the rise in global temperatures to below $2{ }^{\circ} \mathrm{C}$ in the 21 st Century, global emissions have to be reduced significantly more than originally assumed. Fortunately, this aim still seems feasible if the rate of emissions does not exceed the maximum of $44 \mathrm{Gt}$ of carbon dioxide in $2020 .{ }^{34}$

Otherwise, if emissions continue to increase as before, the target of a projected $56 \mathrm{Gt}$ in 2020 would be missed by $12 \mathrm{Gt}$ - also described as the Gt gap. Even if all states honoured their commitments to climate protection, the original aim would be exceeded by $5 \mathrm{Gt} .{ }^{35}$ So what measures have to be taken to meet the original target of $44 \mathrm{Gt}$ ? It is now more necessary than ever to set higher national objectives regarding emission reduction; these can only be realised through internationally binding treaties such as the Kyoto Protocol. Therefore, consistent and robust ways of measurement, reporting and verification of GHG emissions have to be developed. This automatically leads back to the issue of global cooperation and states parties' common but differentiated responsibilities and respective capabilities. ${ }^{36}$ It will take a strong and inclusive effort to address the issue of climate change properly and finally. Thus, the current deadlock has to be overcome. A coalition of the willing is all very well, but without the support of the big polluters, the process is bound to fail. So the challenge for future negotiations and negotiators is threefold:

- There are only two years remaining to reach a consensus on a new treaty. Taking into account the very slow progress from 1990 to 2010, some scepticism may be justified as to whether this is sufficient.

- For such a treaty to achieve its aim, it will be necessary to successfully include countries such as Canada, China, India and the US not only in treaty negotiations, but also in their commitment to signing up, and

34 See http://www.unep.org/annualreport/2011/\#, last accessed 4 December 2012.

35 See Hirsch (2012:15f.).

36 (ibid.:3). 
- Effective and efficient mechanisms will have to be found regarding technical and financial assistance both for developing countries and those most affected by climate change.

\section{Outlook: Is There a Way Forward?}

Climate change can no longer be considered as a political issue that can still be put off until tomorrow. It is all too present, and with its complex multitude of devastating consequences, it is a daily reality for many people - especially the poor. While the international climate debate has, for years, centred on implementing plans and concluding adequate agreements to take into account the interests of all countries - with rather disappointing outcomes - it is high time to rethink this approach. In view of the dramatic increase of disasters caused by the impact of climate change, the focus now has to be shifted to issues such as crisis management and plans for preventative measures to combat further natural disasters, among other things.

It seems clear there is no way other than to initiate a global innovation process aiming to reform our current economic models and come up with new technological and social solutions to the problem of climate change. This has to be done with a long-term perspective. In order to be able to concentrate on these issues it will be necessary to create a climate of trust in which cooperation on an international level is easier than it is presently. So how can we overcome the clashing interests of emerging economies and developing countries in this process?

Developed countries will have to acknowledge their responsibility for the current situation, and they have to financially and technically assist other countries to redress the harm they have done. On the contrary, developing countries will have to realise that their ever-growing economies and the understandable desire of their populations for better living conditions can only be environmentally sustainable if they do not repeat the same mistakes developed and industrialised countries have made over a long period. Developing countries will have to be willing to play an active part in international negotiations while implementing respective measures to counter the impacts of climate change at home. The road to change is by no means an easy route to take. It requires the acknowledgment of two basic facts: we have no time, and climate change and its impacts know no boundaries. These two facts apply to us all. There will also need to be renewed focus on climate change as a highly prioritised political topic. Financial and economic crises are se- 
rious problems and they certainly require our attention, but the impact of climate change will have more far-reaching and long-lasting effects. It is not rocket science to predict that the road to any solution will be a long and winding one. Many frustrations will have to be overcome in the process which will leave a lot of stakeholders dissatisfied.

Perhaps the most important factor remains the individual. The way we behave towards our environment determines not only our future, but also the future of generations to come. The same goes for the political process. As long as voters regard other issues as being more important than climate change, the pressure on political leaders to act and react will not be very significant. So before we point a finger at negotiators and deplore the state of negotiations, we have to ask ourselves whether we, too, have our priorities right. The history of climate change negotiations does not give us much reason to be overly optimistic as far as a comprehensive and speedy solution is concerned. However, the small margin of progress that has been achieved so far proves that success is possible.

\section{References}

Böhringer, Christoph, 2001, Climate Politics from Kyoto to Bonn: From Little to Nothing, ZEW Discussion Papers, No. 01-4, Mannheim, Centre for European Economic Research (ZEW), University of Oldenburg, available at http://hdl.handle.ne/10419/2 4470, last accessed 10 November 2012.

Donner, Susanne \& Felix Faltin, 2007, Klimapolitische Entwicklungen in den USA: Initiativen auf Bundesstaatlicher und Regionaler Ebene, Wiesbaden, Deutscher Bundestag, available at http://www.bundestag.de/dokumente/analysen/2008/Klimapoliti sche_Entwicklung_USA.pdf, last accessed 12 November 2012.

Fuhr, Lili, Barbara Unmüßig \& Hans J.H. Verolme, 2011, A Future for International Climate Politics - Durban and Beyond, Berlin, Heinrich-Böll-Stiftung.

Harris, Paul G., 2010, China and Climate Change: From Copenhagen to Cancun, Washington, D.C., Environmental Law Institute, available at http://www.epa.gov/ogc/chin a/harris.pdf, last accessed 12 November 2012.

Hirsch, Thomas, 2012, Internationale Klimapolitik: Rückblick und künftige Herausforderungen, Bonn, Friedrich-Ebert-Stiftung, Online-Akademie.

Mapaure, Isaac, 2011, Climate Change in Namibia: Projected Trends and Effects, in: Ruppel, Oliver C. \& Ruppel-Schlichting, Katharina (Eds), Environmental Law and Policy in Namibia, Windhoek/Essen, Orumbonde Press \& Welwitschia Verlag Dr A. Eckl, 289-307.

Mayr, Christoph, 2009, Erklärungshilfen zur Entwicklung der internationalen Klimapolitik: Spieltheorie und Public Choice Theorie, Hamburg, Igel Verlag. 
Monbiot, George, 2012, Obama and Romney Remain Silent on Climate Change, the Biggest Issue of All, The Guardian, 5 November 2012, available at http://www.guar dian.co.uk/commentisfree/2012/nov/05/obama-romney-remain-silent-climate-cha nge, last accessed 6 November 2012.

Ritter, Karl, 2012, 2012 UN Climate Talks in Doha, Qatar Face Multiple Challenges, Huffington Post, 25 November 2012, available at http://www.huffingtonpost.com/20 12/11/25/2012-un-climate-talks-qatar_n_2188048.html, last accessed 4 December 2012.

Ruppel, Oliver C., 2013, Gassünder ohne Verantwortung - Der 18. Weltklimagipfel: Verlängerung des Kyoto-Protokolls - Nur Minimalerfolg, Allgemeine Zeitung (Namibia), 08 January 2013, available at http://www.az.com.na/umwelt/umweltsnde r-ohne-verantwortung.161903.php, last accessed 8 January 2013. 